\title{
Knowledge Transfers from Federally Funded Research and Development Centers
}

Department of Economics Working Paper Series

\section{Albert N. Link}

University of North Carolina at Greensboro

March 2021

Working Paper 21-03

economics.uncg.edu 


\title{
Knowledge Transfers from Federally Funded Research and Development Centers
}

\author{
Albert N. Link \\ University of North Carolina at Greensboro \\ anlink@uncg.edu
}




\begin{abstract}
The findings from a study of the relationship between postdoctoral students and R\&D at Federally Funded Research and Development Centers (FFRDCs) are presented in this paper. The goal of the study is not only to understand better knowledge transfers from publicly supported R\&D but also to estimate the returns to $R \& D$ conducted in federally funded laboratories. Using public domain data related to FFRDCs, published by the U.S. National Science Foundation, the R\&D elasticity of doctoral students is estimated over the years 2010 through 2019 to be about 0.85 . This estimate compares well to previous studies of the returns to publicly funded R\&D.
\end{abstract}

Keywords: Program management, FFRDCs, Returns to R\&D, Postdoctoral students, Public sector

JEL Codes: H41, O31, O38 


\section{Knowledge Transfers from Federally Funded Research and Development Centers}

\section{Introduction}

Knowledge transfers from publicly funded research are about ways for publicly funded research results and expertise to enter the economy. The European Commission (2020, p. 16) defines channels to support knowledge transfers to include: "publications and presentations, teaching, networking/events, consultancy ..." These transfer channels reflect the paths through which research results and expertise, which are embodied in individuals, can flow. Many if not most of these channels are conduits for the transfer of tacit knowledge.

In support of the importance of these transfer channels, the European Commission (2020, p. 16) also emphasizes that knowledge transfer channels should "not [emphasis added] be limited to patenting, licensing volume, spinoffs, and commercial revenue." However, these mechanisms are, in fact, the transfer channels that are primarily used by U.S. federal agencies and laboratories under the rubric of technology transfer. ${ }^{1}$

Metrics on these technology transfer mechanisms are reported annually to the President and the Congress by the Technology Partnerships Office within the Department of Commerce. ${ }^{2}$ More specifically, U.S. technology transfers are uniformly characterized in the Office's reports in terms of number of patents, number of licenses, and the number of cooperative research and development agreements (CRADAs) between a federal agency or laboratory and other

\footnotetext{
${ }^{1}$ See Choudhry and Ponzio's (2020) discussion about traditional technology transfer mechanisms.

${ }^{2}$ The Technology Partnerships Office within the National Institute of Standards and Technology (NIST) collects information on these and other technology transfer mechanisms from federal laboratories, aggregated to the agency level. The Office reports these mechanisms to the President and the Congress in the form of an annual report entitled Federal Laboratory Technology Transfer [Fiscal Year]: Summary Report to the President and the Congress. Therein it is written "Although intellectual property has traditionally been tracked in terms of the number of patents, licenses, and collaborative efforts [CRADAs], most federal research results are transferred through publication of S\&E [Science and Engineering] articles." Surprisingly, scientific publication counts are not a metric included across agencies in these annual reports.
} 
organizations. Only the latter mechanism, CRADAs, involves the transfer of intangible knowledge (tacit knowledge as well as codified knowledge) by individuals. ${ }^{3}$

In this paper, I contribute to the knowledge transfer literature through a systematic study of postdoctoral students funded through U.S. federal laboratories. ${ }^{4}$ Individuals completing a postdoctoral experience at a federally funded laboratory are positioned well to transfer their acquired knowledge, as well that their base of experiential knowledge, through publications, presentations, teaching, networking, and so forth. Postdoctoral students at federal funded laboratories are one channel through which knowledge transfer can occur; a mechanism that has yet to be considered, much yet studied, systematically. I also contribute to the returns to public sector R\&D literature through estimates of the R\&D elasticity of postdoctoral students.

The postdoctoral students funded through U.S. federally funded laboratories considered in this paper were located at Federally Funded Research and Development Centers (FFRDCs). Thus, to provide context for this study, a brief history of FFRDCs is presented in Section II. ${ }^{5}$ Motivating this brief history are observations from a Carnegie Mellon University report $(2017$, p. 1) on FFRDCs:

For nearly 70 years, federally funded research and development centers, or FFRDCs, have been vital to our nation's growth and security. They have supported the government by developing transformational capabilities in defense, transportation, energy, civil agency administration, homeland security, atmospheric sciences, science policy, and other areas. Yet their existence remains largely unknown to the average person. Even those familiar with FFRDCs may be hard-pressed to explain their history, purpose, and operation [emphasis added].

\footnotetext{
${ }^{3}$ For a recent discussion of CRADA activity in federal laboratories, see Chen et al. (2018).

${ }^{4}$ For an overview of previous studies on postdoctoral students at universities, see Hayter and Parker (2019).

${ }^{5}$ An understanding of FFRDCs is important for at least two reasons. First, FFRDCs are an important segment of federal laboratories, and federal laboratories undertake a significant portion of basic and applied research in the nonacademic public sector. And second, federal laboratories are an important element of the U.S. national innovation system not only because of the knowledge outputs that emanate from laboratory R\&D but also because their knowledge outputs often complement the knowledge outputs from university R\&D and from private-sector R\&D thus leveraging elements of the U.S. national innovation system.
} 
The analytical model used in this paper to estimate the statistical relationship between the number of postdoctoral students at an FFRDC in a particular year and the R\&D budget of the FFRDC in that fiscal year is presented in Section III. An R\&D elasticity of postdoctoral students is estimated from this model. Such an estimate proxies a measure of the returns to $R \& D$, and this metric is comparable to other R\&D-like elasticity measures. As discussed below, quantifying the returns to $R \& D$ in federal research laboratories has been deemed a national priority. Data on the FFRDC variables that are used to estimate the analytical model are also described in this section.

The empirical findings from the model are presented in Section IV.

The paper concludes in Section V with a discussion of the findings vis-à-vis the literature on the returns to public sector $R \& D$. Also, suggestions for future research related to knowledge transfers as well as technology transfers from federal laboratories is offered.

\section{A Brief History of FFRDCs ${ }^{6}$}

The Act Donating Public Lands to the Several States and Territories which may provide Colleges for the Benefit of Agriculture and the Mechanic Arts, also known as the Morrill Act, was signed by President Abraham Lincoln on July 2, 1862. This act planted the seed, so to speak, for public support of research for the betterment of society. Building on the theme of the Morrill Act, the Hatch Act of 1887 mandated that agriculture experiment stations be established in states that received land under the Morrill Act. Thus, the Hatch Act emphasized publicly funded research as a national objective.

The national focus of public sector supported research began to change after World War I from agriculture to defense and related technologies. Due in large part to the interest and passions of President Franklin D. Roosevelt, the latter emphasis became even more focused during World War II. For example, the President's New Deal program created the National Defense Research

\footnotetext{
${ }^{6}$ This section has benefitted greatly from comments from Peter Blair.
} 
Committee (NDRC) in 1940 to encourage and attract American civilian scientists [emphasis added] for military research with the goal of adapting World War II science and technology for the commonweal. ${ }^{7}$ Vannevar Bush was chairman of the committee. ${ }^{8}$ NDRC was expanded during the following year into the Office of Scientific Research and Development (OSRD).

The purposes of OSRD were, among other things, to: ${ }^{9}$

e. Initiate and support scientific research on the mechanisms and devices of warfare with the objective of creating, developing, and improving instrumentalities, methods, and materials required for national defense.

f. Initiate and support scientific research on medical problems affecting the national defense.

g. Initiate and support such scientific and medical research as may be requested by the Government of any country whose defense the President deems vital to the defense of the United States under the terms of the Act of March 11, 1941, entitled "An Act to Promote the Defense of the United States"; and serve as the central liaison office for the conduct of such scientific and medical research for such countries.

OSRD was charged to implement its functions by utilizing "the laboratories, equipment, and services of governmental agencies and institutions to the extent that such facilities are available for such purposes." In part, it fulfilled its charge through its support of research centers. The first such research center was the Radiation Laboratory at MIT, which became operational just before the formalization of OSRD and which later was renamed Lincoln Laboratories (Dale and Moy, 2000). Another center was the Naval Operations Research Group, which later became the

\footnotetext{
${ }^{7}$ In the leadup to World War II, most of the NDRC's work was highly classified which set precedents that have pluses and minuses to this day.

${ }^{8}$ See https://www.oxfordreference.com/view/10.1093/acref/9780199891580.001.0001/acref-9780199891580-e5391. The creation of the OSRD protracted a debate between Bush and Senator Kilgore (D, WV) over the basic research mission and the applied research mission of a National Science Foundation. See https://www.nsf.gov/about/history/nsf50/nsf8816.jsp.

${ }^{9}$ See https://www.presidency.ucsb.edu/documents/executive-order-8807-establishing-the-office-scientific-researchand-development.
} 
Center for Naval Analysis (Carnegie Mellon, University 2015). According to Carnegie Mellon University (2017, pp. 1-2):

Government agencies recognized the need to maintain and take advantage of a critical mass of science and technology knowledge not otherwise available in the standard civilservice environment ... To achieve this, the government created [what eventually became] the FFRDC model around two key needs and organizing principles. First, these new organizations had to provide the government with access to a specialized, agile workforce available to respond quickly to complex national challenges. Second, they had to operate outside of the standard marketplace, so that commercial conflicts of interest did not compromise their objectivity.

These federal research centers were soon referred to as Federal Contract Research Centers (FCRCs) because their research was done directly through federal contracts. FCRC employees were not federal employees. According to Carnegie Mellon University (2017, p. 5):

\begin{abstract}
As the Cold War became the new reality, government officials and their scientific advisers advanced the idea of a systematic approach to research, development, and acquisitions, one independent of the ups and downs of the marketplace and free of the restrictions on the civil service. From this idea arose the concept of FFRDCs - private entities that would work almost exclusively on behalf of the government, be free of organizational conflicts of interest, and maintain stable workforces composed of highly trained technical talent. With FFRDCs, the government could reliably get the technical, acquisition, or policy guidance it needed while commercial industry continued to manufacture the products and provide necessary services.
\end{abstract}

FFRDCs became a research infrastructure to assist the government make cost effective choices in technology development, policy formation, systems acquisition and integration, and other vital elements of government operations (OTA, 1995). Many scientists after the war did not want to move to military laboratories or did not want to be government employees. They saw benefits being in a university setting or an industrial setting. Thus, FFRDCs were in practice a vehicle through which the federal government could capture this base of scientific knowledge. 
Fundamentally, FFRDCs facilitate cost effectiveness by emphasizing (Carnegie Mellon University, 2017, p. 27):

... a commitment to the public interest, a long-term horizon, and an organizational structure outside of and apart from government, ensuring an absence of conflicts of interest.

In 1967, the FCRCs were formally renamed Federally Funded Research and Development Centers (FFRDCs). ${ }^{10}$ U.S. Federal Acquisition Regulation (FAR 2.101) originally defined an FFRDC in the following manner:

Federally Funded Research and Development Centers (FFRDCs) means activities that are sponsored under a broad charter by a Government agency (or agencies) for the purpose of performing, analyzing, integrating, supporting, and/or managing basic or applied research and/or development, and that receive 70 percent or more of their financial support from the Government. ${ }^{11}$

As OTA noted in its history of the Department of Defense FFRDC (OTA, 1995, pp. 10-11): ${ }^{12}$
All of these terms [federal research centers, FCRCs, and FFRDCs] were labels for diverse entities that were neither federal government agencies nor for-profit companies ... What differentiated these centers from other federal government centers or for-profit defense research companies was a combination of nonfederal government personnel and federal government sponsorship.

\footnotetext{
${ }^{10}$ The Air Force created the organization that became the first FFRDC in 1947. It was RAND (R AND D).

${ }^{11}$ Currently, the activities of a FFRDC are defined in U.S. Federal Acquisition Regulations (FAR) 35.017.

12 Of course, a substantial portion of R\&D in FFRDCs under the Department of Defense is focused on defense, but one should not assume that the knowledge transfers from these laboratories through postdoctoral students is entirely oriented toward defense technology. See Goel, Payne, and Ram (2008). Knowledge transfer occur through various channels, and those channels may not be unique to the umbrella agency. See Brown, Berry, and Goel (1991). Similarly, knowledge transfers from FFRDCs in general will be absorbed differently depending on the untimate home laboratory for the postdoctoral students. See Goel (1990).
} 
Federal laboratories, which are, by definition, government owned (GO) can be distinguished by the characteristic of the laboratory's operational management. GO laboratories can either be government operated $(\mathrm{GO})$ or contractor operated $(\mathrm{CO})$. Thus, federal laboratories are referred to either as GOGO laboratories or GOCO laboratories. All FFRDCs are GOCO laboratories.

FAR 35.017 defines FFRDC contractors (COs) into three groups: universities, industrial firms and organizations, and nonprofit organizations. ${ }^{13}$ The National Science Foundation (NSF) also classifies FFRDCs by activity type. The three activity types are: research and development laboratories, study and analysis centers, and systems engineering and integration centers. ${ }^{14}$ FFRDCs classified as research and development laboratories are the focus of the empirical analysis that follows.

\section{Analytical Model and Data}

The analytical model used to estimate the relationship between the R\&D budget of each FFRDC and the number of its postdoctoral students is:

\footnotetext{
${ }^{13}$ As stated in FAR 35.017: 'FFRDC's are operated, managed, and/or administered by either a university or consortium of universities, other not-for-profit or nonprofit organization, or an industrial firm, as an autonomous organization or as an identifiable separate operating unit of a parent organization." More detailed information about the contractor organizations is listed at https:/www.nsf.gov/statistics/ffrdclist/.
}

14 The National Science Foundation uses the following definitions. "Research and development laboratories fill voids where in-house and private sector research and development centers are unable to meet agency core area needs. Specific objectives for these FFRDCs are to: (1) maintain over the long-term a competency in technology areas where the Government cannot rely on in-house or private sector capabilities, and (2) develop and transfer important new technology to the private sector so the Government can benefit from a wider, broader base of expertise. R\&D laboratories engage in research programs that emphasize the evolution and demonstration of advanced concepts and technology, and the transfer or transition of technology. Study and analysis centers deliver independent and objective analyses and advise in core areas important to their sponsors in support of policy development, decision making, alternative approaches, and new ideas on issues of significance. And system engineering and integration centers provide required support in core areas not available from sponsor's in-house technical and engineering capabilities to ensure that complex systems meet operational requirements. The centers assist with the creation and choice of system concepts and architectures, the specification of technical system and subsystem requirements and interfaces, the development and acquisition of system hardware and software, the testing and verification of performance, the integration of new capabilities, and continuous improvement of system operations and logistics. They often play a critical role in assisting their sponsors in technically formulating, initiating, and evaluating programs and activities undertaken by firms in the for-profit sector." See https://www.nsf.gov/statistics/ffrdelist/. 
(1) $\log$ Postdocs $=\alpha+\beta \log R \& D+\mathbf{X}$

Postdocs is the fiscal year (FY) number of postdocs at a FFRDC, $R \& D$ is the fiscal year R\&D budget (\$2019) of an FFRDC, and $\mathbf{X}$ is a vector of binary variables to control for contractor ownership and other characteristics of the data.

Data on FFRDC Postdocs and $R \& D$ are available from the NSF for all active FFRDCs over the fiscal years 2010, 2012, 2013, 2015, 2017, and 2019. ${ }^{15}$ For these years, information is publicly available for the 42 currently active FFRDCs. Thus, the panel of data has 252 rows (42 identifying rows for each of 6 years) and 2 columns of continuous variables. A few of the currently active FFRDCs were not operational in the earlier years so data on Postdocs and $R \& D$ are not available for those years. Thus, 18 cells in the panel do not contain a datum.

Table 1 defines the variables used in the estimation of equation (1). Table 2 shows descriptive statistics for all of the variables in the complete panel. FFRDCs that are classified as research and development laboratories are the focus of the empirical analysis in this paper; $D m y R D=1$. As an explanation for the focus of this paper on FFRDCs that are classified as research and development laboratories, see the descriptive statistics in Table 3 for all of the variables, especially for the variable Postdocs, segmented by DmyRD. The mean number of Postdocs among non-research and development laboratories $(D m y R D=0)$ is 0 .

Insert Tables 1, 2, and 3 about here

For estimation purposes, as discussed below, equation (1) was specified in logarithmic terms. Postdocs $=0$ was redefined as Postdocs $=.0001$. When Postdocs $=.0001$, the variable DmyPostdocs was set to 1 (0 otherwise) to control for this adjustment to the data. The variable $R \& D$ was converted from millions of current dollars, as reported by NSF, to millions of $\$ 2019$ using the GDP deflator (Jankowski, 1993). Included in vector $\mathbf{X}$ in equation (1) are binary variables to control for differences in the employment of postdoctoral students by the FFRDC's CO.

${ }^{15}$ NSF also publishes information on inactive FFRDCs. See https://www.nsf.gov/statistics/ffrdclist/\#historic. 


\section{The Empirical Findings}

The regression results from the estimation of equation (1) are presented in Table 4.

Insert Table 4 about here

The estimated regression coefficient on $\log R \& D$ in each of the four columns is positive and statistically significant. The estimated coefficients represent values of the R\&D elasticity of postdoctoral students. From the results in column (1), for example, a 10 percent increase in R\&D expenditures in FFRDCs is associated with an 8.48 percent increase in the annual number of funded postdoctoral students. The specification in column (2) includes the variable Trend as a control variable; the estimated elasticity is 8.44 . These estimated elasticities are robust to adjustment through a random-effects model (27 identifying rows for each of 6 years). ${ }^{16}$ See columns (3) and (4).

\section{Discussion and Concluding Remarks}

In the aftermath of the Great Recession, President Barack Obama emphasized the role of federal laboratories in the U.S. economy through his 2011 Presidential Memorandum-Accelerating Technology Transfer and Commercialization of Federal Research Support of High Growth Businesses. ${ }^{17}$ Therein he wrote:

I direct that [federal laboratories] establish goals and measure performance, streamline administrative processes, and facilitate local and regional partnerships in order to accelerate technology transfer and support private sector commercialization.

President Donald Trump, in his The President's Management Agenda: Modernizing Government for the $21^{\text {st }}$ Century set forth a cross agency priority to improve the transfer of technology from laboratories to the market and (Trump, undated, p. 47):

\footnotetext{
${ }^{16}$ I thank my colleague Jeremy Bray for his comments and suggestions related to this random-effects model.

${ }^{17}$ See Link and Oliver (2020) for a discussion of the legislative history leading to the Presidential Memorandum.
} 
... to optimize technology transfer and support programs to increase the return to investment (ROI) from federally funded R\&D.

Table 5 summarizes the recent econometric-based studies of the return to public sector R\&D. ${ }^{18,19}$ All but one of the listed studies focus on the transfer of technical knowledge through patents. The Link and Scott (2021) study looks at knowledge transfer through scientific publications. Link and Scott estimate an R\&D elastic of scientific publications of between a 15.5 and 21.5 percent. The R\&D elasticity of doctoral students estimated herein is about one-half of the value of these estimates; about 8.5 percent.

While the number of studies that offer estimates of the returns to public sector R\&D are increasing, all of the economic-based studies to date suffer from a similar shortcoming, namely the economic consequences of the identified output from R\&D is not considered. For example, How do organizations that license patented technologies developed from public sector R\&D use that technical knowledge and what are the resulting economic consequences? And, How do organizations absorb knowledge from scientific publications or from federally funded postdoctoral students, and what are the resulting economic consequences? Perhaps, through longitudinal case studies more will be learned about the economics of knowledge and technology transfers.

\footnotetext{
${ }^{18}$ I am using the term public sector rather than the term federally funded because some of the studies focused on federal funding through an agency's Small Business Innovation Research (SBIR) program rather than federally funded R\&D performed directly in a federal laboratory. The former is federally funded privately performed R\&D and the latter is federally funded publicly performed R\&D.

${ }^{19}$ The emphasis on econometric-based studies is indented to distinguish these efforts from the long-established efforts of, for example, the National Institute of Standards and Technology (NIST) within the Department of Commerce and the Office of Energy Efficiency and Renewable Energy (EERE) within the Department of Energy to sponsor federally funded program evaluation studies. See https://www.nist.gov/tpo/nist-economic-impact-studies and https://www.energy.gov/eere/analysis/program-evaluation-eere-completed-evaluations. For an excellent example of a recent NIST-sponsored case study, see Leech et al. (2019).
} 
Table 1

Definition of Variables

\begin{tabular}{ll}
\hline Variable & Definition \\
\hline Postdocs & Number of postdoctoral students at an FFRDC \\
$R \& D$ & R\&D expenditures of a FFRDC (millions \$2019) \\
DmyRD & $=1$ if a FFRDC is classified as a research and development FFRDC; 0 otherwise \\
DmyUniv & $=1$ if the contractor (CO) for the FFRDC is a university; 0 otherwise \\
DmyInd & $=1$ if the contractor (CO) for the FFRDC is an industrial firm; 0 otherwise \\
DmyNonP & $=1$ if the contractor (CO) for the FFRDC is a nonprofit organization; 0 \\
& otherwise \\
FY & Fiscal year of the data \\
Trend & $=(2019-F Y)$ \\
DmyPostdocs & $=1$ if Postdocs $=0 ; 0$ otherwise
\end{tabular}

Note: The R\&D data used in this paper come from https://www.nsf.gov/statistics/srvyffrde/\#tabs-2 and the data on postdoctoral students come from https://ncses.nsf.gov/pubs/nsf21305\#data-tables. 
Table 2

Descriptive Statistics on the Variables $(n=234)$

\begin{tabular}{lcccc}
\hline Variable & Mean & $\begin{array}{c}\text { Standard } \\
\text { Deviation }\end{array}$ & Minimum & Maximum \\
\hline Postdocs & 74.436 & 121.017 & 0 & 519 \\
$R \& D$ & 526.809 & 693.114 & 4.633 & 3373.330 \\
DmyRD & 0.658 & 0.475 & 0 & 1 \\
DmyUniv & 0.338 & 0.474 & 0 & 1 \\
DmyInd & 0.115 & 0.320 & 0 & 1 \\
DmyNonP & 0.547 & 0.499 & 0 & 1 \\
Trend & 4.483 & 3.020 & 0 & 9 \\
DmyPostdocs & 0.432 & 0.496 & 0 & 1 \\
\hline
\end{tabular}


Table 3

Descriptive Statistics on the Variables Segmented by DmyRD

$$
\operatorname{DmyRD}=1(\mathrm{n}=154)
$$

\begin{tabular}{lcccc}
\hline Variable & Mean & $\begin{array}{c}\text { Standard } \\
\text { Deviation }\end{array}$ & Minimum & Maximum \\
\hline Postdocs & 113.104 & 133.793 & 0 & 519 \\
R\&D & 688.102 & 769.936 & 12.342 & 3373.217 \\
DmyRD & 1 & -- & 1 & 1 \\
DmyUniv & 0.513 & 0.501 & 0 & 1 \\
DmyInd & 0.175 & 0.381 & 0 & 1 \\
DmyNonP & 0.312 & 0.465 & 0 & 1 \\
Trend & 4.483 & 3.020 & 0 & 9 \\
DmyPostdocs & 0.136 & 0.344 & 0 & 1 \\
\hline
\end{tabular}

$\operatorname{Dmy} R D=1 \quad(\mathrm{n}=80)$

\begin{tabular}{lcccc}
\hline Variable & Mean & $\begin{array}{c}\text { Standard } \\
\text { Deviation }\end{array}$ & Minimum & Maximum \\
\hline Postdocs & 0 & 0 & 0 & 0 \\
$R \& D$ & 216.320 & 347.095 & 4.633 & 1124.861 \\
DmyRD & 0 & -- & 0 & 0 \\
DmyUniv & 0 & 0 & 0 & 1 \\
DmyInd & 0 & 0 & 0 & 1 \\
DmyNonP & 1 & 0 & 0 & 1 \\
Trend & 4.338 & 3.031 & 0 & 9 \\
DmyPostdocs & 1 & 0 & 0 & 1 \\
\hline
\end{tabular}


Table 4

Regression Results from Equation (1) for DmyRD=1, Dependent Variable is log Postdocs (robust standard errors in parentheses; $n=154$ )

\begin{tabular}{|c|c|c|c|c|}
\hline Variable & (1) & (2) & (3) & (4) \\
\hline \multirow[t]{2}{*}{$\log R \& D$} & $0.848 * * *$ & $0.844 * * *$ & $0.809 * * *$ & $0.810 * * *$ \\
\hline & $(0.089)$ & $(0.089)$ & $(0.170)$ & $(0.171)$ \\
\hline \multirow[t]{2}{*}{ DmyUniv } & $0.648 * * *$ & $0.649 * * *$ & 0.799 & 0.780 \\
\hline & $(0.236)$ & $(0.234)$ & $(0.170)$ & $(0.656)$ \\
\hline \multirow[t]{2}{*}{ DmyInd } & $0.876 * * *$ & $0.877 * * *$ & 1.014 & 1.014 \\
\hline & $(0.175)$ & $(0.176)$ & $(0.656)$ & $(0.812)$ \\
\hline \multirow[t]{2}{*}{ DmyPostdocs } & $-12.054 * * *$ & $-12.060 * * *$ & $-10.250 * * *$ & $-10.254 * * *$ \\
\hline & $(0.243)$ & $(0.243)$ & $(0.342)$ & $(0.344)$ \\
\hline \multirow[t]{2}{*}{ Trend } & -- & 0.024 & -- & 0.0004 \\
\hline & & $(0.027)$ & & $(0.012)$ \\
\hline Intercept & $\begin{array}{c}-7.347 * * * \\
(1.246)\end{array}$ & $\begin{array}{c}-7.424 * * * \\
(1.231)\end{array}$ & $\begin{array}{l}-1.708 \\
(1.192)\end{array}$ & $\begin{array}{l}-1.713 \\
(1.193)\end{array}$ \\
\hline R-squared & 0.959 & 0.959 & 0.870 & 0.872 \\
\hline F-level & $859.99 * * *$ & $687.47 * * *$ & -- & -- \\
\hline
\end{tabular}

$* * *$ significant at .10-level, $* *$ significant at .05-level, $*$ significant at .10-level 
Table 5

Recent Literature on the Returns to Public Sector R\&D

\begin{tabular}{|c|c|c|}
\hline Author (by year) & Unit of Observation & Major Finding \\
\hline Pressman et al. (2018) & $\begin{array}{l}\text { U.S. federal laboratories } \\
\text { licensing income data }\end{array}$ & $\begin{array}{l}\text { The total contribution of these } \\
\text { federal laboratory licensors to } \\
\text { industry gross output ranges } \\
\text { from } \$ 23.1 \text { billion to } \$ 76.5 \\
\text { billion in } 2009 \text { U.S. dollars. }\end{array}$ \\
\hline Link (2019) & U.S. NIST data & $\begin{array}{l}\text { A } 10 \% \text { increase in R\&D is } \\
\text { associated with an } 8 \% \text { increase } \\
\text { in patent licensing activity at } \\
\text { NIST. }\end{array}$ \\
\hline Link and Van Hasselt (2019) & $\begin{array}{l}\text { U.S., federal agency data on } \\
\text { SBIR-funded projects }\end{array}$ & $\begin{array}{l}\text { A } 10 \% \text { increase in agency per } \\
\text { capita R\&D is associated with a } \\
10.6 \% \text { increase in new patent } \\
\text { applications by the funding } \\
\text { agencies. }\end{array}$ \\
\hline $\begin{array}{l}\text { Link, Morris, and Van Hasselt } \\
(2019)\end{array}$ & $\begin{array}{l}\text { U.S. Environmental } \\
\text { Protection Agency (EPA) } \\
\text { data }\end{array}$ & $\begin{array}{l}\text { A } 10 \% \text { increase in the one-year } \\
\text { lag of R\&D is associated with } \\
\text { increase of new patent } \\
\text { applications by the EPA of } \\
\text { between } 23.5 \% \text { and } 25.8 \%\end{array}$ \\
\hline Link and Oliver (2020) & $\begin{array}{l}\text { U.S. federal agency data on } \\
\text { R\&D and technology } \\
\text { transfer mechanisms }\end{array}$ & $\begin{array}{l}\text { A } 10 \% \text { increase in the ratio of } \\
\text { R\&D to employees is associated } \\
\text { with a } 5.9 \% \text { increase in new } \\
\text { patent applications by the } \\
\text { funding agencies. }\end{array}$ \\
\hline Link and Van Hasselt (2020) & $\begin{array}{l}\text { U.S. federal agency funded } \\
\text { Phase II Small Business } \\
\text { Innovation Research (SBIR) } \\
\text { projects }\end{array}$ & $\begin{array}{l}\text { A } 10 \% \text { increase in agency per } \\
\text { capita R\&D is associated with a } \\
4.7 \% \text { increase in new patent } \\
\text { applications by the SBIR funded } \\
\text { firms. }\end{array}$ \\
\hline Link and Scott (2021) & $\begin{array}{l}\text { U.S. Federally Funded } \\
\text { Research and Development } \\
\text { Center (FFRDC) } \\
\text { laboratories }\end{array}$ & $\begin{array}{l}\text { A } 10 \% \text { increase in FFRDC } \\
\text { R\&D is associated with a } 21.5 \% \\
\text { increase in scientific } \\
\text { publications. }\end{array}$ \\
\hline
\end{tabular}




\section{References}

Brown, M.A., G.G. Berry, and R.K. Goel (1991). “Guideline for Successfully Transferring Government-Sponsored Innovations," Research Policy, 20: 121-143.

Carnegie Mellon University (2017). FFRDCs: A Primer, Pittsburgh: Carnegie Mellon University.

Chen, C., A.N. Link, and Z.T. Oliver (2018). "U.S. Federal Laboratories and their Research Partners: A Quantitative Case Study," Scientometrics, 115: 501-517.

Choudhry, V. and T.A. Ponzio (2020). "Modernizing Federal Technology Transfer Metrics," Journal of Technology Transfer, 45: 544-559.

Dale, B.C. and T.D. Moy (2000). The Rise of Federally Funded Research and Development Centers, Albuquerque, NM: Sandia National Laboratories.

European Commission (2020). Knowledge Transfer Metrics: Towards a European-Wide Set of Harmonized Indicators, Luxembourg: European Union.

Goel, R.K. (1990). "The Substitutability of Capital, Labor, and R\&D in U.S. Manufacturing," Bulletin of Economic Research, 42: 211-227.

Goel, R.K., J.E. Payne, and R. Ram (2008). "R\&D Expenditures and U.S. Economic Growth: A Disaggregated Approach," Journal of Policy Modeling, 30: 237-250.

Hayter, C.S. and M.P. Parker (2019). "Factors that Influence the Transition of University Postdocs to Non-academic Scientific Careers: An Exploratory Study, Research Policy, 48: $556-570$.

Jankowski, J.E., Jr. (1993). “Do We Need a Price Index for Industrial R\&D?” Research Policy, 22: 195-205.

Leech, D.P., S. Ferris, and J.T. Scott (2019). "The Economic Impacts of the Advanced Encryption Standard, 1996-2017,"' Annals of Science and Technology Policy, 3: 142-257.

Link, A.N. (2019). "Technology Transfer at the U.S. National Institute of Standards and Technology," Science and Public Policy, 46: 906-912.

Link, A.N., C.A. Morris, and M. van Hasselt (2019). “The Impact of Public R\&D Investments on Patenting Activity: Technology Transfer at the U.S. Environmental Protection Agency," Economics of Innovation and New Technology, 28: 536-546. 
Link, A.N. and M. van Hasselt (2019). "A Public Sector Knowledge Production Function," Economics Letters, 175: 64-66.

Link, A.N. and M. van Hasselt (2020). "Exploring the Impact of R\&D on Patenting Activity in Small Women-Owned and Minority-Owned Entrepreneurial Firms," Small Business Economics, 54: 1061-1066.

Link, A.N. and Z.T. Oliver (2020). Technology Transfer and U.S. Public Sector Innovation, Northampton, MA: Edward Elgar Publisher.

Link, A.N. and J.T. Scott (2021). "Scientific Publications at U.S. Federal Research Laboratories," Scientometrics, DOI: 10.1007/s11192-020-03854-2.

Office of Technology Assessment (1995). A History of the Department of Defense Federally Funded Research and Development Centers, OTA-BP-ISS-157, Washington, DC: Government Printing Office.

Pressman, L., M. Planting, R. Yuskavage, J. Bond, and C. Moylan (2018). “A Preliminary Application of an I-O Economic Impact Model to US Federal Laboratory Inventions: 20082015," Gaithersburg, MD: U.S. National Institute of Standards and Technology.

Trump, President Donald (undated). The President's Management Agenda, https://www.whitehouse.gov/omb/management/pma/. 